Revisão / Review

\title{
Leucemia de grandes linfócitos granulares
}

\section{Large granular lymphocyte leukemia}

Bruno Terra

Amanda M. Maia ${ }^{2}$
O presente estudo tem como objetivo o estabelecimento de fundamentação teórica atualizada baseada em revisão bibliográfica sobre a leucemia de grandes linfócitos granulares ( $L G L G)$, doença onco-hematológica, que, devido à sua relativa raridade, é pouco conhecida e subdiagnosticada. A LGLG é caracterizada pela proliferação clonal de linfócitos T ou NK na medula óssea elou no sangue periférico. Dentre as manifestações clínico-laboratoriais, podem ocorrer citopenias (anemia elou neutropenia elou plaquetopenia), linfocitose (não costuma ser acentuada), linfadenomegalia, hepatoesplenomegalia, alterações imunológicas e sintomas constitucionais (emagrecimento, febre e sudorese). O curso clínico da LGLG é bastante variável, sendo que no subtipo T costuma ser indolente ou oligossintomática, enquanto no subtipo NK a evolução costuma ser desfavorável. O diagnóstico é firmado através de imunofenotipagem por citometria de fluxo e estudo de clonalidade por métodos de biologia molecular. Seu tratamento é bastante diversificado e é definido de acordo com a apresentação clínica da doença. Rev. Bras. Hematol. Hemoter. 2010;32(2):141-148.

Palavras-chave: Leucemia linfocitica granular grande; linfocitose; neutropenia.

\section{Introdução}

Os grandes linfócitos granulares (GLGs) constituem um distinto subtipo de células linfoides, representando cerca de 10\%-15\% do total de células mononucleares no sangue periférico de um adulto. ${ }^{1}$ A maioria destas células (85\%) é derivada da linhagem de linfócitos natural killer (NK) CD3-, sendo as $15 \%$ restantes provenientes da linhagem de linfócitos $\mathrm{T} \mathrm{CD}^{+}$. Estes últimos representam in vivo os linfócitos T citotóxicos ativados, enquanto os primeiros (NK) pertencem ao sistema imune inato que media a citotoxicidade restrita às células sem expressão do complexo principal de histocompatibilidade.

Em 1977 foi inicialmente descrita uma síndrome caracterizada pela proliferação de GLGs associados à neutropenia, ${ }^{1,2}$ e desde então vários estudos referentes à proli- feração dos GLGs têm sido publicados. A leucemia de grandes linfócitos granulares (LGLG) como desordem clonal foi primeiramente descrita em 1985, envolvendo sangue periférico, medula óssea e baço. ${ }^{3}$ Nos anos seguintes foram reconhecidos dois principais subtipos de LGLG, de acordo com a célula envolvida, T ou NK, ambas com potencial de doença agressiva ou indolente.

As LGLG T e NK entraram, então, na classificação das malignidades linfoides, estando hoje presentes como entidades distintas na classificação da Organização Mundial da Saúde - OMS (WHO - World Health Organization), como pode ser observado no Quadro $1 .^{4}$

As proliferações de GLGs podem também representar situações benignas, policlonais, reacionais às infecções virais, doenças autoimunes, neoplasias malignas e póstransplante de órgão. Estas proliferações benignas podem

\footnotetext{
${ }^{I}$ Médico Hematologista - Unidade de Alta Complexidade em Oncologia de Itabuna - Oncosul/BA.

${ }^{2}$ Biomédica. MsC - Laboratório de Célula-tronco/Centro de Transplante de Medula Óssea - Inca/RJ.

Instituto Nacional do Câncer - Rio de Janeiro-RJ

Correspondência: Amanda de Moraes Maia

Laboratório de Célula-tronco, Centro de Transplante de Medula Óssea (Cemo), Instituto Nacional do Câncer (Inca)

Praça da Cruz Vermelha 23, $6^{\circ}$ andar - Centro

20230-130 - Rio de Janeiro-RJ - Brasil

Tel: (55 21) 2506-6874; Fax: (55 21) 2509-2121

E-mail:amaia@inca.gov.br

Doi: 10.1590/S1516-84842010005000034
} 
Quadro 1. Classificação de neoplasias linfoides de células T maduras e de células NK segundo a Organização Mundial de Saúde (2008)

Neoplasias de células T maduras e de células NK

Leucemia prolinfocítica de células $T$

Leucemia de grandes linfócitos granulares de células $T$

Desordem linfoproliferativa crônica de células NK

Leucemia de células NK agressiva

Doença linfoproliferativa sistêmica de células T da infância EBV+

Linfoma "Hydroa vacciniforme-like"

Leucemia/linfoma de células $\mathrm{T}$ do adulto

Linfoma de células NK/T extranodal, do tipo nasal

Linfoma de células $T$ associado à enteropatia

Linfoma hepatoesplênico de células T

Linfoma de células T subcutâneo "panniculitis-like"

Micose fungoide

Síndrome de Sézary

Desordens linfoproliferativas de células $\mathrm{T}^{\mathrm{CD}} 30^{+}$primário da pele Papulomatose linfomatoide

Linfoma anaplásico de grandes células primário da pele

Linfoma de células T gama-delta primário da pele

Linfoma de células T citotóxico epidermotrópico agressivo CD8+ primário da pele

Linfoma de células T CD4+ pequeno/médio primário da pele

Linfoma de células $T$ periférico, NOS

Linfoma de células $T$ angioimunoblástico

Linfoma anaplásico de grandes células, $\mathrm{ALK}^{+}$

Linfoma anaplásico de grandes células, ALK'

Fonte: adaptado da classificação da $\mathrm{OMS}^{4}$

ser transitórias (com resolução espontânea ou após o tratamento da doença de base), ou então se tornam crônicas. ${ }^{1}$ $\mathrm{Na}$ maioria dos casos reacionais, o linfócito $\mathrm{T}$ é o subtipo envolvido.

A metodologia utilizada para o desenvolvimento deste trabalho foi a de pesquisa bibliográfica com coleta de informações sobre a LGLG em livros-texto de Hematologia e base de dados eletrônicos (PubMed: www.ncbi.nlm.nih.gov/ pubmed/), com procura dirigida aos termos "T-Large Granular Lymphocyte Leukemia", "NK-Large Granular Lymphocyte Leukemia" e "Large Granular Lymphocyte Leukemia".

Foram selecionados artigos de revisão, relatos de casos, artigos enfocando metodologias diagnósticas, artigos descrevendo terapêutica e evolução clínica. Não houve limite de data de publicação.

\section{Epidemiologia}

A LGLG compreende cerca de $2 \%-5 \%$ de todas as malignidades de células T ou NK. A forma LGLG-T indolente representa mais de $80 \%$ dos casos, com maior acometimento entre os idosos. Indivíduos mais jovens são os mais acometidos pelo subtipo LGLG-NK agressiva (com média de 39 anos ao diagnóstico), com maior número de casos descritos na Ásia e América do Sul. ${ }^{1}$ Não há predileção por sexo.

\section{Etiologia e patogênese}

A etiologia da LGLG ainda é desconhecida. Postula-se que mecanismos autogênicos ou antígenos virais possam levar à ativação das células $\mathrm{T}$, levando cronicamente a um estímulo que ocasionaria a síntese aumentada de GLGs. ${ }^{5,6} \mathrm{O}$ vírus HTLV II já foi detectado e implicado como possível agente etiológico em poucos pacientes com LGLG, mas sabese atualmente que a maioria dos portadores de LGLG não tem sorologia reagente para HTLV I ou II. ${ }^{1}$

$\mathrm{O}$ vírus Epstein-Barr (EBV) pode estar relacionado à patogênese da LGLG-NK agressiva. ${ }^{7}$ Tem sido proposta a teoria de que esta modalidade de LGLG seja uma variante leucêmica do linfoma de células NK/T (tipo nasal), que tem sabidamente relação com a infecção pelo EBV. Há, ainda, a possibilidade de associação com doenças autoimunes, nas quais, por estímulo antigênico crônico, pode ocorrer uma proliferação exagerada de um só clone de célula T citotóxica CD8. ${ }^{8,9}$

A proliferação clonal de células linfoides T e NK foi recentemente descrita em pacientes em uso de dasatinibe, droga inibidora da tirosina-quinase utilizada no tratamento da leucemia mieloide crônica. ${ }^{10,11}$

\section{Características clínicas}

A apresentação clínica da doença dependerá essencialmente do subtipo citológico envolvido, podendo ser: 1) LGLG-T indolente, 2) LGLG-T variante agressiva, 3) LGLGNK agressiva, 4) Linfocitose NK crônica indolente.

Na LGLG-T indolente são comuns as citopenias (principalmente a neutropenia, gerando risco de infecções recorrentes). A esplenomegalia (normalmente leve a moderada) acomete $20 \%-50 \%$ dos pacientes, e a hepatomegalia é evidente em 10\%-20\% dos casos. Já a linfadenomegalia é mais rara. Febre, sudorese noturna e perda de peso (sintomas B) se manifestam em 20\%-40\% dos pacientes. Dentre os portadores de LGLG-T indolente é comum a associação com doenças autoimunes, especialmente a artrite reumatoide, a qual pode estar presente em até 30\% dos casos.

A variante agressiva da LGLG-T é raramente diagnosticada e seu quadro clínico muito se assemelha ao da LGLGNK agressiva, apresentação mais grave dentre as LGLGs, com citopenias severas, hepatoesplenomegalia, linfocitose e linfadenomegalia, sintomas B, e por vezes síndrome hemofagocítica. Também já foram descritos envolvimento do trato gastrointestinal ${ }^{12,13}$ e acometimento renal. ${ }^{14}$

Ao contrário, a linfocitose NK crônica indolente tem bom prognóstico, poucas vezes havendo citopenias, vasculite cutânea, neuropatia periférica ou esplenomegalia. $^{15}$ 
Quadro 2. Sintomas clínicos e prognóstico de pacientes com LGLG, de acordo com o subtipo apresentado

\begin{tabular}{|c|c|c|}
\hline Subtipo & Sintomas & Prognóstico \\
\hline LGLG-T indolente & $\begin{array}{c}30 \% \text { : assintomáticos } \\
70 \% \text { : sintomáticos (citopenias, hepatoesplenomegalia, } \\
\text { sintomas B, doenças autoimunes) }\end{array}$ & Bom \\
\hline LGLG-T agressiva & $\begin{array}{c}100 \% \text { sintomáticos } \\
\text { (citopenias, hepatoesplenomegalia, sintomas B, linfadenomegalia) }\end{array}$ & Ruim \\
\hline LGLG-NK agressiva & $\begin{array}{c}100 \% \text { sintomáticos } \\
\text { (citopenias, hepatoesplenomegalia, sintomas B, linfadenomegalia) }\end{array}$ & Muito ruim \\
\hline Linfocitose NK crônica & $\begin{array}{c}60 \% \text { : assintomáticos } \\
40 \% \text { : sintomáticos (citopenias, vasculite cutânea, } \\
\text { neuropatia periférica, esplenomegalia) }\end{array}$ & Bom \\
\hline
\end{tabular}

Fonte: adaptado de Sokol e Loughran

\section{Características hematológicas}

A hematoscopia torna-se essencial quando suspeitase de LGLG. Os GLGs são células de tamanho médio a grande, com citoplasma abundante, levemente basofílicos, com grânulos azurófilos, com núcleo periférico na maioria das vezes (Figura 1). Porém, em alguns casos, os linfócitos têm morfologia atípica, e o diagnóstico só é confirmado através da imunofenotipagem.
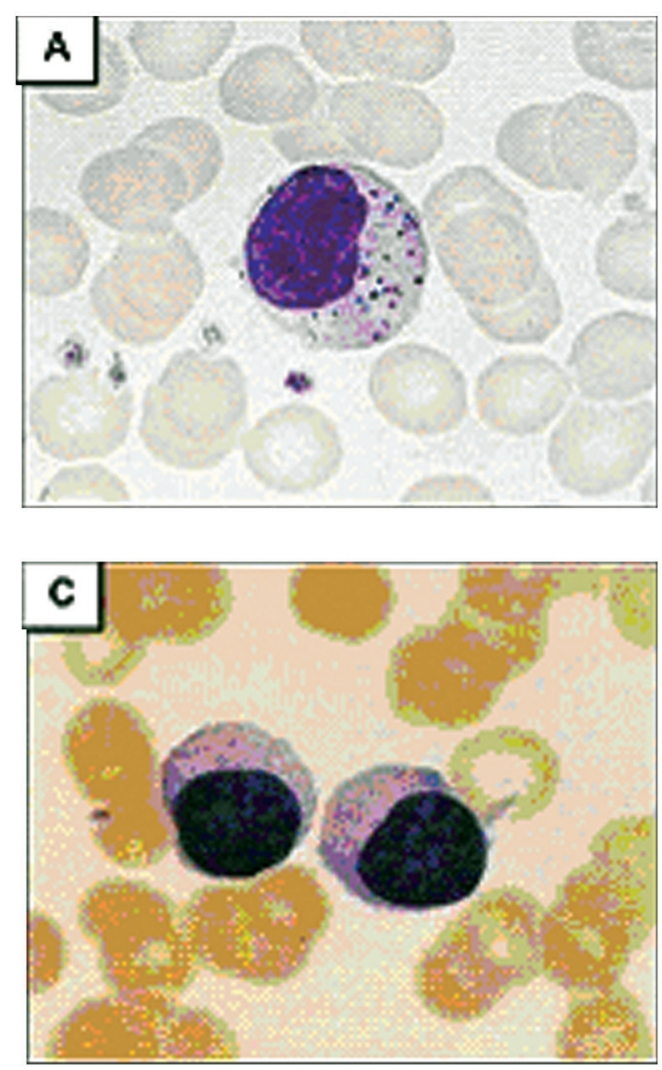

Não há consenso sobre o número absoluto de GLGs necessário para o diagnóstico; estudos prévios já sugeriram contagem $>1,0 \times 10^{9} / 1,{ }^{2}$ ou contagem $>2,0 \times 10^{9} / 1 .{ }^{16}$ Por vezes, o aumento do valor absoluto dos GLGs só é evidenciado meses após a suspeita clínica. A maioria dos pacientes com LGLG-T tem neutropenia crônica, sendo que metade tem contagem de neutrófilos $<0,5 \times 10^{9} / 1 .^{12} \mathrm{~A}$ anemia está presente em cerca de $50 \%$ destes pacientes. A aplasia pura de células vermelhas e a anemia hemolítica autoimune podem ocorrer.
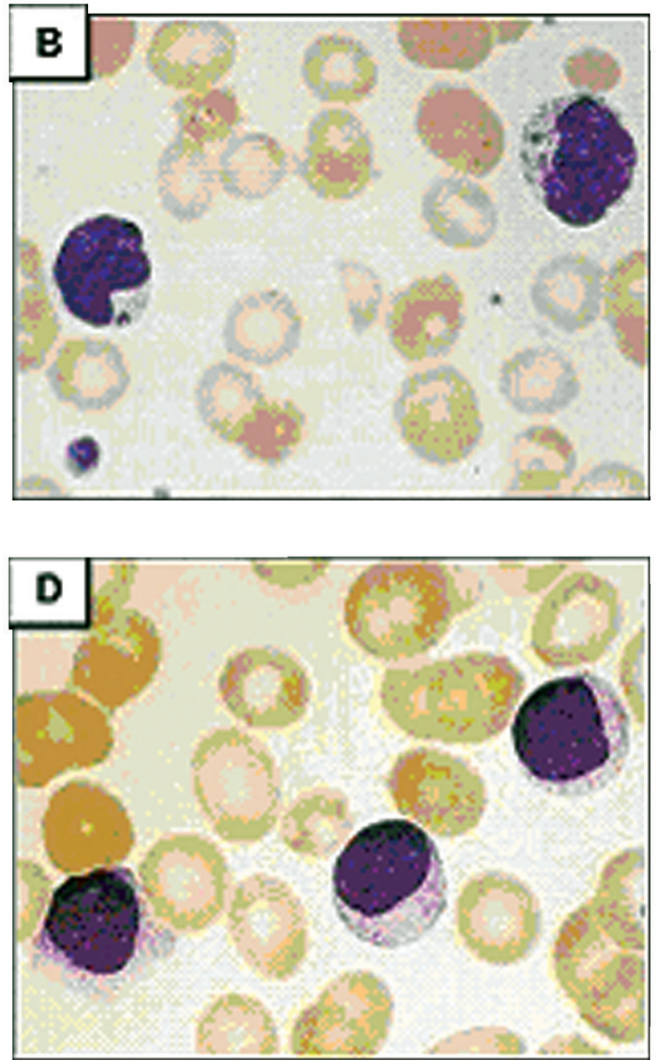

Figura 1. Grandes linfócitos granulares em sangue periférico com coloração HE. Em (A) e (B) GLGs com granulação azurofílica habitual; em (C) e (D) GLGs com granulação fina 
No caso dos pacientes com LGLG-NK, a neutropenia severa é mais rara, porém a anemia está presente em quase $100 \%$ dos casos. ${ }^{12}$ As trombocitopenias severas também são mais comuns nas LGLG-NK; na LGLG-T a trombocitopenia costuma ser moderada (quando presente).

Diferentes mecanismos têm sido propostos para explicar as citopenias presentes na doença. Em relação à neutropenia (citopenia mais comumente encontrada), há hipótese de destruição direta dos precursores mieloides, alteração na maturação dos mesmos, destruição periférica dos neutrófilos e até indução de apoptose como resultado de ativação via Fas/FasL. ${ }^{17,18}$ Em relação à anemia e à trombocitopenia, pode haver inibição dos precursores na medula óssea, destruição periférica (Anemia hemolítica autoimune no caso das hemácias e púrpura trombocitopênica imune no caso das plaquetas). Há ainda a possibilidade de sequestro esplênico nos pacientes que têm esplenomegalia. ${ }^{19}$ A proliferação de GLGs pode estar ligada à inibição do seu mecanismo de apoptose, com acúmulo destas células na medula óssea e no sangue periférico.

A biópsia osteomedular e o mielograma não são essenciais para o diagnóstico, ${ }^{16}$ sendo a imunofenotipagem por citometria de fluxo do sangue periférico e o estudo da clonalidade as peças-chave para o diagnóstico. No entanto, a abordagem medular pode conferir aspectos peculiares úteis quando há dúvida diagnóstica.

No aspirado medular não há um aspecto padrão a ser encontrado. Nem sempre serão visualizadas as características típicas dos GLGs, pois à realização do esfregaço pode haver contração do citoplasma destes linfócitos, o que dificulta a visualização dos grânulos citoplasmáticos. ${ }^{20}$ Não há determinação da porcentagem de GLGs necessária para o diagnóstico, até mesmo porque nem sempre há infiltração difusa da medula óssea.

À biópsia osteomedular são comumente visualizados infiltrados linfocíticos intersticiais nos casos de LGLG-T, achado que pode ser também encontrado em linfocitoses reacionais ${ }^{21}$ como nos casos de infecções e doenças autoimunes. Neste caso, a imuno-histoquímica pode ser valiosa no diagnóstico diferencial. Os marcadores CD8, TIA-1 e Granzima B podem estar presentes, individualmente, ou em conjunto. ${ }^{20,22}$ Já a LGLG-NK ainda não está bem caracterizada à imuno-histoquímica.

Tanto na LGLG-T quanto na LGLG-NK podem ainda ser verificados, à biópsia osteomedular, parada de maturação no setor granulocítico e aplasia eritroide. Em relação à quantificação da celularidade global, a medula óssea pode estar hipo-, normo- ou hipercelular. ${ }^{21}$

\section{Imunofenotipagem}

A imunofenotipagem, realizada através da análise de biomarcadores no sangue periférico com anticorpos por citometria de fluxo, tem fundamental papel no diagnóstico e
Quadro 3. Painel de marcadores imunofenotípicos de acordo com o subtipo de LGLG

\begin{tabular}{lcccccc}
\hline & CD3 & CD4 & CD8 & CD16 & CD56 & CD57 \\
\hline LGLG-T & + & - & + & + & - & + \\
LGLG-NK & - & - & - & + & + & - \\
LGLG-T agressiva & + & - & + & + & + & $+/-$ \\
$\begin{array}{l}\text { Linfocitose } \\
\text { crônica NK }\end{array}$ & - & - & - & + & + & - \\
\hline
\end{tabular}

Legenda: (+) apresenta a expressão do marcador; (-) não apresenta a expressão do marcador; (+/-) pode ou não apresentar a expressão do marcador

na distinção entre LGLG-T e LGLG-NK. É habitualmente utilizado um painel com os marcadores CD3, CD4, CD8, CD16, CD56, CD57 e, algumas vezes, HLA-DR.

Como pode ser observado no Quadro 3, a citometria de fluxo em pacientes com LGLG-T apresenta $\mathrm{CD}^{+}, \mathrm{CD} 4, \mathrm{CD} 8^{+}$, $\mathrm{CD} 16^{+}, \mathrm{CD} 56, \mathrm{CD}^{2} 7^{+}$e, algumas vezes, HLA-DR ${ }^{+}$. A variante agressiva de LGLG-T costuma expressar $\mathrm{CD}^{+} \mathrm{e}$ CD56 $6^{+} .{ }^{12,23}$

Na LGLG-NK, o painel imunofenotípico evidencia na maior parte das vezes CD3, CD4, CD8, CD16 , CD56 , CD57. Não é possível diferenciar a LGLG-NK agressiva da linfocitose crônica de células NK, pois o imunofenótipo é o mesmo.

\section{Clonalidade}

A pesquisa de clonalidade da LGLG no sangue periférico também tem fundamental importância no diagnóstico, sendo utilizados como métodos a reação de polimerase em cadeia (PCR) ou o Southern blotting. Ambos têm como objetivo confirmar a clonalidade dos GLGs, os quais, na LGLG$\mathrm{T}$, se desenvolvem a partir de uma única célula patológica, com o mesmo padrão genético de rearranjo TCR (receptor de células T); o mesmo não pode ser aplicado para as células NK, as quais não sofrem o padrão de rearranjo TCR como nas LGLG-T, tornando mais complicada a confirmação da clonalidade. Uma nova classe de receptores de células NK foi recentemente detectada na superfície destas células. Trata-se da killer-cell immunoglobulin-like receptor, ou KIRs, ${ }^{24}$ cuja expressão aberrante tem sido demonstrada em alguns casos de LGLG, com potencial de tornar-se possível teste de confirmação de clonalidade NK.

\section{Citogenética}

São ainda escassos os estudos citogenéticos nos casos de LGLG, provavelmente por conta da raridade dos casos, e também devido à dificuldade de se obterem metáfases em linfócitos já diferenciados. ${ }^{25}$ Nos poucos relatos de casos de LGLG-T com anormalidades cromossômicas bem estudadas, já foram encontradas inversão do $12 \mathrm{p} \mathrm{e} 14 \mathrm{q}$, deleção do $5 \mathrm{q}$, trissomia do ${ }^{8,3,14}$ Em relação às LGLG-NK, já há relatos que revelam cariótipo complexo, assim como deleção do $6 \mathrm{q} .{ }^{1}$ 


\section{Anormalidades imunológicas e relação com doenças autoimunes}

Pacientes com LGLG-T frequentemente têm alterações imunológicas humorais ${ }^{12}$ incluindo positividade para fator reumatoide, anticorpos antinucleares, imunocomplexos circulantes, anticorpos antineutrófilos e hipergamaglobulinemia monoclonal. Este mesmo grupo de pacientes pode ter também alteração na imunidade celular, como diminuição da atividade NK. ${ }^{3}$ A razão para estas anormalidades ainda não está bem estabelecida, embora postule-se que a presença de células malignas $\mathrm{T} \mathrm{CD} 8^{+}$possa levar à alteração funcional dos linfócitos B . Dentre os pacientes com LGLG-NK, tais alterações ainda não foram descritas.

A associação com doenças autoimunes é frequente nos portadores de LGLG-T. Já foi descrita coexistência de LGLG$\mathrm{T}$ com artrite reumatoide, síndrome de Sjögren, lúpus eritematoso sistêmico e tireoidite de Hashimoto. A síndrome de Felty, caracterizada pela tríade constituída por artrite reumatoide, esplenomegalia e neutropenia, pode representar a associação entre a LGLG-T e a artrite reumatoide. Alguns autores advogam que esta síndrome possa ser apenas uma variante da LGLG-T. ${ }^{1}$

Não há, até o momento, associação de LGLG-NK com doenças autoimunes.

\section{Critérios diagnósticos}

Em 2006, Sokol e Loughan ${ }^{1}$ propuseram quatro critérios diagnósticos bem definidos:

Critério A: aumento persistente de GLGs no sangue periférico, cuja contagem pode revelar de 2 a $20 \times 10^{9} / 1$. Em até $1 / 3$ dos casos, porém, podem ser encontradas contagens de GLGs $<0,5 \times 10^{9} /$.

Critério B: imunofenótipo típico à citometria de fluxo

Critério $C$ : clonalidade; hoje este critério beneficia apenas os casos de LGLG-T, onde é válido o método (PCR ou Southern blotting) que evidencia o rearranjo TCR; outros métodos estão sendo testados para caracterizar a clonalidade das células NK na LGLG-NK.

Critério D: apresentação clínica; tem importante papel no diagnóstico, pois ajuda na diferenciação entre processos clonais e processos reacionais; nos casos de LGLG-T especial atenção para citopenias, esplenomegalia e artrite reumatoide; nos casos de LGLG-NK, citopenias e sinais de doença aguda, sintomas B (febre, emagrecimento e sudorese), e organomegalia.

Os critérios A, B e C devem estar necessariamente presentes para diagnóstico da LGLG-T. Nos casos onde há dúvida sobre a imunofenotipagem ou sobre a clonalidade, estando o paciente bem, pode-se aguardar e repetir os exames após alguns meses. A abordagem da medula óssea também pode ser útil nos casos duvidosos, assim como nos casos em que há pancitopenia, para que seja afastada coexistência com outras doenças hematológicas, como a síndrome mielodisplásica. ${ }^{18}$

Nos casos de LGLG-NK não podemos incluir a clonalidade como critério diagnóstico; nestes casos, torna-se importante a associação dos dados clínicos aos critérios Ae B.

\section{Diagnóstico diferencial}

O diagnóstico diferencial deve ser feito com patologias nas quais possa ser encontrada linfocitose ( $\mathrm{T}$ ou NK ) policlonal, como 1) doenças autoimunes, especialmente artrite reumatoide, 2) infecções virais (citomegalovírus, HIV, vírus Epstein-Barr, vírus das hepatites B e C), 3) púrpura trombocitopênica imune, ${ }^{2}$ 4) síndrome hemofagocítica, ${ }^{2}$ 5) neoplasias hematológicas (síndrome mielodisplásica, linfoma não Hodgkin) e tumores sólidos. ${ }^{26}$

Há, ainda, os casos nos quais se encontra uma distinta população de GLGs clonais, sem que haja desenvolvimento dos sintomas associados à LGLG. Como exemplo há a TCUS (clonopatia de células $\mathrm{T}$ de significado indeterminado), nomenclatura sugerida por Sabnami e Tsung, em 2006, ${ }^{27}$ para o diagnóstico de trinta pacientes nos quais foi evidenciada a presença de linfócitos $\mathrm{T}$ clonais, com discretas alterações hematológicas (anemia, neutropenia ou plaquetopenia) e, em sua grande maioria, sem sintomas constitucionais. Situação semelhante foi descrita por Schwab e col, em 1997, , $^{28}$ com achado de clonalidade T ou NK em idosos assintomáticos. Há ainda relatos de linfocitose T ou NK encontrada em alguns pacientes submetidos a transplante de órgãos..$^{29}$ Uma pequena expansão clonal de células $\mathrm{T}$ já foi descrita também em algumas doenças hematológicas nas quais há, aparentemente, supressão hematopoética mediada por linfócitos T, como anemia aplásica, ${ }^{30}$ hemoglobinúria paroxística noturna ${ }^{18}$ e síndrome mielodisplásica. ${ }^{31,32}$

\section{Tratamento}

Devido à raridade dos diagnósticos, o tratamento das LGLG ainda é baseado em relatos de casos e pequenos estudos retrospectivos de algumas instituições. ${ }^{33}$

\section{Tratamento da $L G L G-T$}

Grande parte dos pacientes portadores de LGLG-T não necessita de tratamento após o diagnóstico, sendo necessário somente controle clínico-laboratorial. Remissões espontâneas já têm sido reportadas. ${ }^{34}$ Os sintomas decorrentes de citopenias severas (anemia sintomática, infecções recidivantes e sangramentos) e o agravamento de sintomas constitucionais (sintomas B) são os que costumam deflagrar o início do tratamento.

Dentre os quimioterápicos, habitualmente são recomendados o metotrexato em doses baixas $\left(10 \mathrm{mg} / \mathrm{m}^{2}\right.$ por semana) ou a ciclofosfamida (50-100 mg/dia), ambos com 
possibilidade de administração por via oral. Via de regra, a monoquimioterapia é eficaz, embora em alguns pacientes haja demora de até quatro meses para que se evidencie resposta, motivo pelo qual é recomendado que, se possível, não se modifique o tratamento nos primeiros quatro meses na ausência de resposta. ${ }^{1}$

Foi observado que, nos pacientes que respondem bem à monoquimioterapia em baixas doses (metotrexato e ciclofosfamida), com melhora das citopenias, nem sempre há expressiva diminuição dos GLGs no sangue periférico e/ou na medula óssea. Este dado sugere que a principal ação dos quimioterápicos nestes casos não é a citotoxicidade, mas sim a ação imunossupressora/imunomodulatória. Já foi observada redução do FasL circulante nos pacientes em tratamento bem sucedido. ${ }^{12}$

A recidiva das citopenias ou dos sintomas constitucionais é comum quando interrompido o tratamento, o que faz com que, em boa parcela dos casos, seja necessário o uso do quimioterápico por tempo indefinido. Já foi relatado o uso de fludarabina em um pequeno grupo de pacientes, com administração de dois a seis ciclos mensais, com obtenção de boa resposta a curto prazo sem recidiva após a interrupção do tratamento. ${ }^{35}$ Novos estudos prospectivos são necessários para definição do papel da fludarabina como tratamento de $1^{\mathrm{a}}$ ou $2^{\mathrm{a}}$ linha nas LGLG-T.

Além dos quimioterápicos acima, já foram também relatadas boas respostas terapêuticas com 2-deoxicoformicina (pentostatina) ${ }^{33}$ e 2-cloroxiadenosina (cladribina), ${ }^{1}$ ambas usadas habitualmente em pacientes refratários ao tratamento de $1^{\mathrm{a}}$ ou $2^{\mathrm{a}}$ linha.

Algumas teorias já estão sendo propostas para a quimiorrefratariedade evidente em alguns pacientes. Uma pesquisa com um pequeno grupo de portadores de LGLG visando o estudo da expressão fenotípica de resistência a múltiplas drogas revelou a expressão de $\mathrm{PgP}$ (glicoproteínas P) e de LRP (lung resistance protein - proteína de resistência do pulmão) em $100 \%$ e $70 \%$ (respectivamente) dos pacientes estudados, sugerindo que estas proteínas estejam presentes em grande parte dos portadores de LGLG ${ }^{36}$ A relevância clínica deste dado ainda não está bem estabelecida.

O anticorpo monoclonal anti-CD52 (alemtuzumab), já aprovado para uso na leucemia linfoide crônica, surge como possibilidade terapêutica para os pacientes com LGLG refratários à $1^{\mathrm{a}}$ ou $2^{\mathrm{a}}$ linha de tratamento, ${ }^{37}$ desde que haja expressão fenotípica do CD52 à citometria de fluxo, ${ }^{38} \mathrm{o}$ que parece acontecer em boa parte dos casos. ${ }^{39}$ Os fatores de crescimento hematopoéticos G-CSF (fator de crescimento de colônia de granulócitos) e GM-CSF (fator de crescimento de colônia de granulócitos/macrófagos) têm sido utilizados com sucesso como $1^{\mathrm{a}}$ linha de tratamento nos pacientes com neutropenia, com boa resposta inclusive durante episódios de infecção. ${ }^{40}$

A terapia imunossupressora com globulina antitimócito (ATG) e/ou ciclosporina pode ser eficaz nos pacientes que apresentam citopenias refratárias. ${ }^{41}$ Ainda são poucos e inconsistentes os casos relatados com este tipo de abordagem terapêutica.

O uso de corticoide (prednisona), isolado ou em combinação com ciclofosfamida ou ATG já foi descrito em poucos casos de LGLG-T com citopenia(s), com boa resposta. ${ }^{41,42}$

A esplenectomia, raramente utilizada como modalidade terapêutica de $1^{\text {a }}$ linha, já foi utilizada com sucesso em casos de LGLG-T associada à anemia hemolítica autoimune ${ }^{43}$ e púrpura trombocitopênica imune. ${ }^{1}$ A esplenectomia pode também ser uma solução (ao menos parcial) para citopenias não autoimunes associadas à esplenomegalia, com diminuição das necessidades transfusionais. ${ }^{44}$

O transplante de células-tronco hematopoéticas (autólogo e alogênico) ainda não tem seu papel bem definido no tratamento da LGLG-T, e fica aparentemente reservado para os pacientes mais jovens refratários aos tratamentos convencionais. ${ }^{45}$

\section{Tratamento da LGLG-NK}

Para os pacientes portadores de LGLG-NK que apresentam-se oligossintomáticos, com evolução clínica mais favorável, pode-se tentar os esquemas terapêuticos descritos para os casos de LGLG-T.

Já para os portadores de LGLG-NK com curso clínico mais agressivo tem sido utilizada a poliquimioterapia, como o esquema CHOP (ou similares), e ainda esquemas mais agressivos, como os usados para leucemia linfoide aguda, seguido ou não de transplante de células-tronco hematopoéticas. ${ }^{1}$ Ainda assim, o prognóstico destes pacientes é bastante ruim, com tempo de sobrevida normalmente inferior a dois meses após o diagnóstico. ${ }^{12}$

\section{Conclusão}

Apesar dos avanços na etiopatologia, diagnóstico e tratamento, o conhecimento acerca da LGLG ainda apresenta lacunas a serem preenchidas, dificultando sua plena caracterização. A raridade da doença, por si só, leva à falta de conhecimento sobre a própria e ao subdiagnóstico, sendo poucas vezes lembrada como diagnóstico diferencial nas linfocitoses ou nas citopenias. A necessidade de exames como imunofenotipagem e teste de clonalidade, restritos a pouquíssimos centros, torna seu diagnóstico ainda mais limitado. Estudos acessórios, como citogenética e imuno-histoquímica de biópsia de medula óssea também não estão totalmente caracterizados e poderão, futuramente, ajudar no diagnóstico e prognóstico.

A decisão em relação à terapêutica dos pacientes com LGLG carece de informações valiosas, como um sistema de estadiamento próprio, assim como de outros índices prognósticos, como estudos citogenéticos. A realização de mais estudos prospectivos e o esclarecimento dos fatores prognósticos poderão levar a uma escolha mais individualizada 
de tratamento, a fim de trazer maior benefício e menor morbidade a seus portadores.

\begin{abstract}
This is a literature review about large granular lymphocyte leukemia (LGLL), a rare and misdiagnosed oncohematological disease, characterized by a clonal expansion of T-cells (T-LGLL) or NK-cells (NK-LGLL) in the bone marrow and/or peripheral blood. The clinical features of LGLL include cytopenias (anemia, neutropenia and thrombocytopenia), lymphocytosis (usually discrete), lymphadenopathy, hepatomegaly, splenomegaly, immune abnormalities and constitutional symptoms (fever, night sweats and weight loss). The diagnosis is based on the confirmation of the clonality of T-cells or NK-cells (polymerase chain reaction and Southern blot are the two methods most commonly used) and typical findings of the immunophenotypic analysis of peripheral blood lymphocytes (flow cytometry analyses for specific surface antigens). In contrast to the chronic and indolent course of T$L G L L, N K-L G L L$ has an acute presentation and poor clinical outcome. There are different current treatment options, depending on clinical presentation. Rev. Bras. Hematol. Hemoter. 2010;32(2): 141-148.
\end{abstract}

Key words: Leukemia, large granular lymphocytic; lymphocytosis; neutropenia.

\section{Agradecimentos}

Agradecemos à Dra. Jane Dobbin, chefe do Serviço de Hematologia do Instituto Nacional de Câncer (Inca), e ao Dr. Ernesto de Meis, médico do Serviço de Hematologia do Instituto Nacional de Câncer (Inca), pela revisão do texto e pelo estímulo.

\section{Referências Bibliográficas}

1. Sokol L, Loughran TP Jr. Large granular lymphocyte leukemia. Oncologist. 2006;11(3):263-73.

2. Lamy T, Loughran TP Jr. Large Granular Lymphocyte Leukemia. Cancer Control. 1998;5(1):25-33.

3. Loughran TP Jr, Kadin ME, Starkebaum G, Abkowitz JL, Clark EA, Disteche $\mathrm{C}$, et al. Leukemia of large granular lymphocytes: association with clonal abnormalities and autoimmune neutropenia, thrombocytopenia, and hemolytic anemia. Ann Intern Med. 1985; 102(2):169-75

4. Jaffe ES, Harris NL, Stein H, Isaacson PG. Classification of lymphoid neoplasms: the microscope as a tool for disease discovery. Blood. 2008; 112(12):4384-99.

5. Epling-Burnette PK, Loughran TP Jr. Survival signals in leukemic large granular lymphocytes. Semin Hematol. 2003;40(3):213-20.

6. Zambello R, Trentin L, Facco M, Cerutti A, Sancetta R, Milani A, et al. Analysis of the $\mathrm{T}$ cell receptor in the lymphoproliferative disease of granular lymphocytes: superantigen activation of clonal CD3+ granular lymphocytes. Cancer Res. 1995;55(24):6140-5.

7. Hart DN, Baker BW, Inglis MJ, Nimmo JC, Starling GC, Deacon E, et al. Epstein-Barr viral DNA in acute large granular lymphocyte (natural killer) leukemic cells. Blood. 1992;79(8):2116-23.
8. O'Keefe CL, Plasilova M, Wlodarski M, Risitano AM, Rodriguez AR, Howe E, et al. Molecular analysis of TCR clonotypes in LGL: a clonal model for polyclonal responses. J Immunol. 2004; 172 (3):1960-9.

9. Wlodarski MW, O'Keefe C, Howe EC, Risitano AM, Rodriguez A, Warshawsky I, et al. Pathologic clonal cytotoxic T-cell responses: nonrandom nature of the T-cell-receptor restriction in large granular lymphocyte leukemia. Blood. 2005;106(8):2769-80.

10. Mustjoki S, Ekblom M, Arstila TP, Dybedal I, Epling-Burnette $\mathrm{PK}$, Guilhot F, et al. Clonal expansion of T/NK-cells during tyrosine kinase inhibitor dasatinib therapy. Leukemia. 2009;23 (8):1398-405

11. Kim DH, Kamel-Reid S, Chang H, Sutherland R, Jung CW, Kim $\mathrm{HJ}$, et al. Natural killer or natural killer/T cell lineage large granular lymphocytosis associated with dasatinib therapy for Philadelphia chromosome positive leukemia. Haematologica. 2009;94(1):135-9.

12. Loughran TP, Kadin ME. Large granular lymphocyte leukemia. In: Beutler E, et al. Loughran \& Kadin, 2001. Hematology. McGraw-Hill, 6th ed; 2001; pp. 1203-5.

13. Hwang YY, Leung AY, Ng IO, Chan GS, Chan KW, Tse E, Kwong YL. Protein-losing enteropathy due to T-cell large granular lymphocyte leukemia. J Clin Oncol. 2009;27(12):2097-8.

14. Christopoulos PD, Katsoudas S, Androulaki A, Nakopoulou L, Economopoulos T, Vlahakos DV. T-cell large granular lymphocyte leukemia presenting as end-stage renal disease: the diagnostic role of flow-cytometric and clonality analysis of the urine sediment. Clin Nephrol. 2009;71(2):198-202.

15. Rabbani GR, Phyliky RL, Tefferi A. A long-term study of patients with chronic natural killer cell lymphocytosis. Br J Haematol 1999;106(4):960-6.

16. Loughran TP Jr. Clonal diseases of large granular lymphocytes. Blood. 1993;82(1):1-14.

17. Berliner N, Horwitz M, Loughran TP Jr. Congenital and acquired neutropenia. Hematology Am Soc Hematol Educ Program. 2004:63-79.

18. Mohan SR, Maciejewski JP. Diagnosis and therapy of neutropenia in large granular lymphocyte leukemia. Curr Opin Hematol. 2009; 16(1):27-34.

19. Lamy T, Loughran TP Jr. Clinical features of large granular lymphocytes leukemia. Semin Hematol. 2003;40(3):185-95.

20. Dogan A, Morice WG. Bone marrow histopathology in peripheral T-cell lymphomas. Br J Haematol. 2004;127(2):140-54.

21. Morice WG, Kurtin PJ, Tefferi A, Hanson CA. Distinct bone marrow findings in T-cell granular lymphocytic leukemia revealed by paraffin section immunoperoxidase stains for CD8, TIA-1, and granzyme B. Blood. 2002;99(1):268-74.

22. Neben MA, Morice WG, Tefferi A. Clinical features in T-cell vs. natural killer-cell variants of large granular lymphocyte leukemia. Eur J Haematol. 2003;71(4):263-5.

23. Camagna A, Cedrone L, Caré A, Samoggia P, De Marco MC, Del Luca $\mathrm{P}$, et al. Polyclonal expansion of CD3(+)/CD4(+)/CD56(+) large granular lymphocytes and autoimmunity associated with dysregulation of Fas/FasL apoptotic pathway. Br J Haematol. 2001; 112(1):204-7.

24. Zambello R, Semenzato G. Natural killer receptors in patients with lymphoproliferative diseases of granular lymphocytes. Semin Hematol. 2003;40(3):201-12.

25. Wong KF, Chan JC, Liu HS, Man C, Kwong YL. Chromosomal abnormalities in T-cell large granular lymphocyte leukaemia: report of two cases and review of the literature. Br J Haematol. 2002;116(3):598-600. 
26. Schleinitz N, Brunet C, Pascal V, Potie C, Veit V, Paul P, et al. A CD4+ V(beta)13.6+ CD56+ large granular lymphocyte expansion with decreased expression of CD95 and an indolent clinical course. Haematologica. 2002;87(11):ECR35.

27. Sabnani I, Tsang P. Are clonal T-cell large granular lymphocytes to blame for unexplained haematological abnormalities? Br J Haematol. 2007;136(1):30-7.

28. Schwab R, Szabo P, Manavalan JS, Weksler ME, Posnett DN, Panettier C, et al. Expanded CD4+ and CD8+ T cell clones in elderly humans. J Immunol. 1997;158(9):4493-9.

29. Halwani F, Guttmann RD, Ste-Croix H, Prud homme GJ. Identification of natural suppressor cells in long-term renal allograft recipients. Transplantation. 1992;54(6):973-7.

30. Lai DW, Loughran TP Jr, Maciejewski JP, Sasu S, Song SX, EplingBurnette PK, Paquette RL. Acquired amegakaryocytic thrombocytopenia and pure red cell aplasia associated with an occult large granular lymphocyte leukemia. Leuk Res. 2008;32(5):823-7.

31. Karadimitris A, Li K, Notaro R, Araten DJ, Nafa K, Thertulien R, et al. Association of clonal T-cell large granular lymphocyte disease and paroxysmal nocturna haemoglobinuria $(\mathrm{PNH})$ : further evidence for a pathogenetic link between $\mathrm{T}$ cells aplastic anemia and PNH. Br J Haematol. 2001;115(4):1010-4.

32. Huh YO, Medeiros LJ, Ravandi F, Konoplev S, Jorgensen JL, Miranda RN. T-cell large granular lymphocyte leukemia associated with myelodysplastic syndrome: a clinicopathologic study of nine cases. Am J Clin Pathol. 2009;131(3):347-56.

33. Tsirigotis P, Venetis E, Kapsimali V, Rontogianni D, Varvitsioti E, Pappa V, et al. 2-Deoxycoformicin in the treatment of T-large granular lymphocyte leukemia. Leuk Res 2003;27(9):865-7.

34. Shichishima T, Kawaguchi M, Ono N, Oshimi K, Nakamura N, Maruyama Y. Gammadelta T-cell large granular lymphocyte (LGL) leukemia with spontaneous remission. Am J Hematol. 2004;75 (3):168-72.

35. Sternberg A, Eagleton H, Pillai N, Leyden K, Turner S, Pearson D. et al. Neutropenia and anemia associated with T-cell large granular lymphocyte leukemia responds to fludarabine with minimal toxicity. Br J Haematol. 2003;120:699-701.

36. Lamy T, Drenou B, Fardel O, Amiot L, Grulois I, Le Prise PY, et al. Multidrug resistance in lymphoproliferative disease of large granular lymphocytes. Br J Haematol. 1998;100(3):509-15.

37. Rosenblum MD, LaBelle JL, Chang CC, Margolis DA, Schauer DW, Vesole DH. Efficacy of alemtuzumab treatment for refractory T-cell large granular lymphocytic leukemia. Blood 2004; 103 (5):1969-71.
38. Mohan SR, Clemente MJ, Afable M, Cazzolli HN, Bejanyan N, Wlodarski MW, et al. Therapeutic implications of variable expression of CD52 on clonal cytotoxic T cells in CD8+ large granular lymphocyte leukemia. Haematologica. 2009;94(10): 1407-14.

39. Osuji N, Del Giudice I, Matutes E, Morilla A, Owusu-Ankomah K, Morilla R, et al. CD52 expression in T-cell large granular lymphocyte leukemia - implications for treatment with alemtuzumab. Leuk Lymphoma. 2005;46(5):723-7.

40. Weide R, Heymanns J, Köppler H, Tiemann M, Huss B, Pflüger $\mathrm{KH}$, et al. Successful treatment of neutropenia in T-LGL leukemia (Tgamma-lymphocytosis) with granulocyte colony-stimulating factor. Ann Hematol. 1994;69(3):117-9.

41. Go RS, Tefferi A, Li CY, Lust JA, Phyliky RL. Lymphoproliferative disease of granular $\mathrm{T}$ lymphocytes presenting if as aplastic anemia. Blood. 2000;96(10):3644-6.

42. Go RS, Li CY, Tefferi A, Phyliky RL. Acquired pure red cell aplasia associated with lymphoproliferative disease of granular $\mathrm{T}$ lymphocytes. Blood. 2001;98(2):483-5.

43. Gentile TC, Loughran TP Jr. Resolution of autoimmune hemolytic anemia following splenectomy in CD3+ large granular lymphocyte leukemia. Leuk Lymphoma. 1996;23(3-4):405-8.

44. Subbiah V, Viny AD, Rosenblatt S, Pohlman B, Lichtin A, Maciejewski JP. Outcomes of splenectomy in T-cell large granular lymphocyte leukemia with splenomegaly and cytopenia. Exp Hematol. 2008;36(9):1078-83.

45. Toze CL, Shepherd JD, Connors JM, Voss NJ, Gascoyne RD, Hogge $\mathrm{DE}$, et al. Allogeneic bone marrow transplantation for low-grade lymphoma and chronic lymphocytic leukemia. Bone Marrow Transplant. 2000;25(6):605-12.

Avaliação: Editor e dois revisores externos

Conflito de interesse: sem conflito de interesse

Recebido: 20/05/2009

Aceito após modificações: 15/11/2009 